Southern Illinois University Carbondale

OpenSIUC

2011

\title{
The Daily Brew: The Structural Evolution of the Coffee Party on Facebook During the 2010 United States Midterm Election Season
}

Christopher Mascaro

Drexel University, cmascaro@gmail.com

Sean P. Goggins

Drexel University, outdoors@acm.org

Follow this and additional works at: http://opensiuc.lib.siu.edu/pnconfs_2011

\section{Recommended Citation}

Mascaro, Christopher and Goggins, Sean P., "The Daily Brew: The Structural Evolution of the Coffee Party on Facebook During the 2010 United States Midterm Election Season" (2011). 2011. Paper 9.

http://opensiuc.lib.siu.edu/pnconfs_2011/9 


\title{
The Daily Brew: The Structural Evolution of the Coffee Party on Facebook During the 2010 United States Midterm Election Season
}

\author{
Christopher M. Mascaro \\ Drexel University, College of Information Science and Technology, cmascaro@gmail.com \\ Sean P. Goggins \\ Drexel University, College of Information Science and Technology, outdoors@acm.org
}

Prepared for the Political Networks Conference, University of Michigan, June 17-18, 2011

\begin{abstract}
The activity of the Facebook Group, "Join the Coffee Party Movement" (Coffee Party) is studied during a 7-month period leading up to and following the 2010 United States Midterm election. During this time, Coffee Party Facebook page administrators posted 872 parent posts that received 152,762 comments from group members. Utilizing our previously established method (Mascaro \& Goggins, 2011) for extracting and analyzing electronic trace data, we constructed a weighted social network from the parent posts and associated comments. We measured network centralization and total post activity for the entire network and identified individuals with high betweenness centrality across three dimensions: 1) Time, 2) Parent Post Category and 3) Specific Parent Posts. We report three key findings. First, the structure, centralization and leadership within the network differ in four key time periods: the time preceding the midterm election, the week of the midterm election, the time immediately following the midterm election and the time period when the new Congress was sworn in. Second, the Coffee Party Administrators act as agenda setters with the parent posts, but show significant variation in their comment participation over time. Third, participants in the discourse alter their discourse role according to specific parent post and category. Our findings have implications for issue groups and candidates who utilize social media tools to mobilize support and engage with supporters.
\end{abstract}

Keywords: Social Network Analysis, Digital Ethnography, Methods, Political Science, Social Media, Social Networking, Online Political Groups, Facebook 


\section{Introduction}

The utilization of technology for disseminating information and mobilizing individuals is rapidly evolving. Social networking sites, allow for the creation of groups that facilitate information exchange and discourse on a variety of topics. We present an analysis of the participation of actors and the networks they create as a result of participation in the Join the Coffee Party Movement (Coffee Party), Facebook group. The Coffee Party started as a Facebook group in January 2010. Initially the group existed only on Facebook, but it quickly moved to the physical world to mobilize support and spread its message of open, civil dialogue related to challenges facing the United States.

Our analysis of the Coffee Party builds on previous research by the authors by analyzing a longer time period of group activity (Mascaro \& Goggins, 2011). The time period of our analysis includes August 1, 2010 - February 28, 2011 and reflects a politically active time that includes the 2010 midterm election, the lame duck session of Congress and the seating of a new Republican controlled House of Representatives. The analysis of the Coffee Party is done through the construction of a social network utilizing a previously established method of analyzing electronic trace data that takes into account the behavior of actors within a group and their interactions with each other in the context of the group.

Using social network analysis to understand large-scale group behavior addresses recent calls for more research in political science pertaining to technologically-mediated networks of actors (Lazer, 2011). We also build on prior work that utilizes social network analysis methods to understand comment streams. Previous research on the networks and discussion participation within online discussion forums has focused on comments streams in USENET forums and Slashdot (Gonzalez-Bailon, S., Kaltenbrunner, A., and Banchs, R. E. 2010, Fiore, LeeTiernan, 
Smith 2002, Gomez, Kaltenbrunner, Lopez, 2008). These studies have relied on the construction of networks and analysis of participation based on explicit connections made through replies to other previous posts. These studies do not acknowledge or examine the importance of implicit connections made in groups where replies are not always explicitly addressed to specific others.

Although Facebook does allow for such explicit direction of comments as previously studied in older technologies, a majority of the individuals do not utilize these discourse techniques (Mascaro, Novak \& Goggins, under review). We address the implicit connections formed within a discussion thread by weighting comments based on time and proximity on a page when a comment is being contributed. The incorporation of time and proximity of comments on a page and their relationship to preceding comments allows for the construction of a weighted social network of 28,975 actors. This weighted social network is created using three dimensions: day $(n=213)$, individual parent post $(n=872)$ and categories of parent post $(n=25)$. Categories were derived using open and axial coding of parent posts for salient themes (Glaser \& Strauss, 1967).

The utilization of different units of analysis allows for a better understanding of the activity of the Coffee Party Administrators and the group participants. The implicit connections that are developed within the comment streams allow for the identification of a set of core individuals who participate in different ways within the group. Through our analysis we identify three key findings. First, the network structure of the group varies greatly over the course of the timeframe that correlates to the different stages of the political process; the time preceding the midterm election, the week of the election, the time following the midterm election, and the time period in which the recently elected candidates take office. Second, the Coffee Party Administrators act as agenda setters with the parent posts that are included on the main page by 
choosing to include specific news articles and information. The Coffee Party Administrators also affect the network structure by participating in the discourse in different ways at different times; sometimes as participant observers and at other times as moderators. Third, contributors to the discourse choose take on different roles, depending on the specific parent post. These differences are all visible in the network centralization and network structure for each of the specific units of analysis. Additionally, there is a small subset of individuals identified through social network measures that emerge as "issue entrepreneurs" by only actively participating in a categorical subset of parent posts (Agre, 2004). These findings have numerous implications for the analysis of issue groups and political candidates who utilize social media to engage with citizens and to mobilize support.

\section{Literature Review}

Social Networks and Conversational Discourse

Individuals that participate in online groups do so in different contexts. Leadership in groups is defined as "behavior or communication that influences, guides, directs, or controls a group" (Bebbe \& Masterson, 2009). Leaders play an integral role in shaping the group as it evolves. Leadership is identified both by implicit and explicit activity. Leaders in online forums are best identified by the number of messages they initiate and the language they utilize (Cassell, Huffaker, Tversky, \& Ferriman, 2006). Though leaders help to shape the dialogue, other participants become more influential as the group develops and interaction begins to deviate from the initial topics (Hersey \& Blanchard, 1992). In Facebook Groups, such as the Coffee Party, the posting of specific news articles as parent posts, participation in discourse or a combination of both establish individuals as leaders.

Social Networks in the physical world are an integral part of information flow and discourse. Individuals often rely on their social networks for news about their surroundings, but 
also for information pertaining to matters important to them, such as health information (Spink \& Cole, 2001). An individual's immediate social network allows them to overcome resource barriers for information gathering by utilizing other individuals to obtain necessary information. The utilization of these networks for information influences the type and scope of the information that individuals receive. These benefits translate to the political domain.

Political discourse between individuals increases political participation in the electoral process. This interaction can occur both within formal group structures and through informal information interactions (McClurg, 2003). Individuals that interact with each other are likely to be of the similar demographic and are likely to have similar value structures as a result of the context of the interaction (Feld, 1982; Marsden, 1987). This similarity of individuals with a shared context and shared "in-group" identity allows for the formulation of relationships that have a greater influence on each other (Tajfel \& Turner, 1986).

The a priori existence of shared contexts of individuals based on demographics helps to contribute to a shared set of information between individuals. Lazer et al. (2010) found that individuals do not rely on political views as a basis for relationship formation, but shift their political attitudes towards those of their social contacts after a relationship is formed. Further, this shift in political attitudes allows for the emergence of a core group of individuals with one set of viewpoints and a periphery of individuals with opposing viewpoints that withdraw from the core. These findings build upon previous research that illustrated the importance of social relationships in political information exchange and discourse (Huckfeldt \& Sprague, 1987). This shared context of information is mimicked in online social networking group membership. Individuals with certain viewpoints will join and form a core network of participants while those who do not share these viewpoints will not join or if they do join these individuals will use it as a 
place to participate in debates about the stated platform of the group.

Research on the behavioral effects of social networks on political activity has been concentrated on the effects of physical social networks. Currently, social networking sites allow for individuals to participate in an online space in numerous ways. Numerous political groups exist within these technologies, allowing individuals to participate in discourse with the administrators and with other members of the group. To engage in direct conversation with others in these open spaces, individuals utilize direct addressals through the technological affordance of the "@” symbol, followed by a name to denote the individual for whom the message is intended. Individuals also utilize more commonplace conversation mechanisms such as the individual's first name without the preceding @. These messages form a subset of interactions within the parent posts and when analyzed together these posts form a subnetwork of conversation. These networks of conversation are more explicitly identified than previous research on conversations within larger scale forums and allow for a much richer analysis of the networks of discourse that emerge (Fisher, Smith, \& Welser, 2006).

\section{Political Engagement on the Internet}

Online social networking sites provide a unique context to the study of networks of political behavior as they extend the network of individuals one can interact with. In $2010,73 \%$ of adult Americans utilized the Internet to get political information or participate in a campaign in some manner. Overall, $22 \%$ of adult Internet users in the United States used social networking sites or Twitter to participate in the election process (Rainie, 2011). These statistics show a significant increase in the numbers from the 2008 election and illustrate the importance of technology in facilitating political activity. 
Early research on political groups on the Internet within USENET groups found that political discussion within USENET groups was more popular than in other groups (Hill \& Hughes, 1997). Specific activity within these groups found that leaders of discussion threads play an integral role in facilitating the discussion by both initiating topics and continuing to participate as the discussion develops. More recent research on USENET illustrates that such technologies expose individuals to other political and cultural viewpoints even when individuals choose to only associate with one group (Kelly, Fisher, \& Smith, 2005). This exposure is the result of crosscutting discussion threads between individuals of different viewpoints within the context of a group with a specific viewpoint. This activity can lead to heated discourse. Recent research on political discussions within non-political groups has also found that political discussions tend to be more active than others (Gonzalez-Bailon, Kaltenbrunner, \& Banchs, 2010).

Early studies have found that social networking sites, specifically Facebook, were used primarily for the maintenance of relationships created in the physical world. As a result of the strong connection to the physical world, the individuals using these websites represented themselves in a truthful manner compared to the participation in other Internet forums (Lampe, Ellison, \& Steinfeld, 2006; Ellison, Steinfeld, \& Lampe, 2007; Lampe, Ellison, \& Steinfeld, 2007). This honesty made the discourse and activity that occurred on these social networking sites much more influential as individuals had physical social capital at stake (Coleman, 1988). Later studies on the usage of Facebook Groups in the university setting found that Facebook Groups were a place for university students to participate in political discourse and information gathering behavior (Valenzuela, Park, \& Kee, 2009). These studies, however, still maintained a connection to social capital in the physical world because they were bounded to a university 
setting.

In 2006 as it was opening its membership up to more individuals, Facebook introduced Election Pulse, a portion of the website that allowed individuals to engage in political behavior pertaining to the 2006 campaign. This further developed Facebook and social networking sites in general as a place for political behavior. Analysis of Facebook's utilization in the 2006 and 2008 elections demonstrated that candidates that utilized Facebook did realize electoral gains that were attributable to the website (Williams \& Gulati, 2007; Williams \& Gulati, 2008; Williams \& Gulati, 2009). The establishment of Election Pulse helped to establish Facebook's place as a tool for future election cycles, and drew the attention of issue groups and political candidates as a place for establishing a presence.

Even with the focus on and welcoming of political activity on Facebook, previous research of political discourse and candidate activity has been limited. Early research of political activity on social networking sites analyzed the Facebook walls of 67 Democratic and Republican candidates in the 2006 United States midterm election and found that individuals utilize these technologies to engage with other supporters in a shallow manner (Sweetser \& Weaver Lariscy, 2008). Analysis of the 2008 Presidential campaign found that individuals utilized these social networking sites to post and share information with others and to discuss topics of interest. This activity equated Facebook walls to that of a virtual town square (Robertson, Vatrapu, \& Medina, 2009; Kavanaugh, Perez-Quinones, Tedesco, \& Sanders, 2010; Robertson, Vatrapu, \& Medina, 2010). Further research on Facebook groups has found that individuals do participate in discourse considered constructive even in groups that are controversial in nature (Kushin \& Kitchener, 2009).

The existing literature illustrates the presence of numerous threads of prior research that 
inform the analysis of conversational discourse on the Internet; but these activities do not occur in a bubble. The context of the group and the backgrounds of its participants play a significant role in the direction and tone of the conversation. The context of parent posts that are associated with a controversial topic space allows for an interesting examination of the attitudes and views of individuals in a politically affiliated group. The findings presented here demonstrate a significant initial contribution to our understanding of interactions within an online group in the political domain; and demonstrate how individuals and group leadership shape these interactions through their rate of participation and the relationship between their specific activities and salient news events.

\section{The Coffee Party}

This paper uses the Facebook group Join the Coffee Party Movement (Coffee Party), a political organization in the US that began as a Facebook Group (Join the Coffee Party Movement), to further understand the network structure of an online political group. Annabel Park, a documentary filmmaker, formed the group as a response to the Tea Party Movement in the United States on January 26, 2010. The group was initially established as an experimental place for civil online deliberation for individuals who sought to engage with other, like-minded individuals. The critical mass of Facebook and the initial popularity surrounding the Coffee Party as an answer to the popular Tea Party movement helped it gain traction and become an active space.

From its inception on January 26, 2010 through April 1, 2011, the Facebook group "Join the Coffee Party Movement" had amassed over 355,000 followers who posted 271,004 comments in direct response to 1,808 official Coffee Party parent posts. Over 977,400 "likes" were registered to these posts during the same period. On Facebook, being a follower is a low 
commitment form of group membership and a "like" is a single click mechanism for voicing agreement or support of a parent post or comment. In addition to participation on the main page, Facebook followers of the Coffee Party movement also set up 171 local Facebook groups, with followers of their own.

Moving from the virtual world to the physical world, The National Coffee Party drew 350 participants to its first convention in September 2010. Through Facebook, the Coffee Party has also orchestrated numerous "National Meeting Days", during which local chapters met at coffeehouses to attempt to move the group from Facebook into the physical world. A "founding members" donation drive in early March 2011, raised over \$115,000. In Spring 2011, the Coffee Party began to develop its next set of goals identified as "Coffee Party 2.0," that includes holding elections for a Board of Directors and further developing its purpose and function on the Internet. Analysis of this activity is outside of the scope of this paper and is the subject of ongoing research.

We study The Coffee Party because it exemplifies a new form of virtual political organization in the contemporary US. The organization is rooted online, but directed to action in the physical world, similar to many recent campaigns for elected office. Such organizations appear to lower the barriers to entry for political organizers by effectively using social and participatory media like Facebook. Groups such as the Coffee Party can utilize social media to engage disparate groups of individuals who share a set of values and allow them to engage with each other in the Facebook Page that the Coffee Party calls its "virtual town hall."

\section{Methods and Sample}

We use the Coffee Party Facebook Group (Join the Coffee Party Movement) as a vehicle to understand the agenda setting activity, networks of participation and discourse in an online political group. All of the parent posts that contained more than 25 comments and the associated 
comments from the Coffee Party Facebook group were collected during the timeframe of August 12010 , - February 28, 2011. The authors determined the selection criterion of more than 25 comments as a filter to enable the establishment of a network of comments for each parent posts. Only 32 parent posts were excluded through this selection criteria and analysis of activity within the excluded comments indicates that the parent posts were mostly informational and the resulting comments were very shallow.

The total sample examined 872 parent posts and 152,762 comments, and included 28,975 participants. Each parent post and its associated comments were collected no less than 6 days after the initial posting to allow for the maturation of discourse. A random sample of parent posts were revisited 2 months after the initial collection and no further comments were identified as being added to the end of the discourse illustrating the likelihood of significant additions to the comment streams as being low.

The parent posts and comments were then parsed using a custom built script used in previous analysis of Facebook groups (Mascaro \& Goggins, 2011). Following the parsing, the parent posts were coded through a process of open coding for salient theme of the parent post until saturation (Glaser \& Strauss, 1967; Charmaz, 2006). In total, there were 25 codes applied to the 872 parent posts. Each parent post received one code, except in the instance when the parent post had an explicit call for action (Code: Mobilization, $\mathrm{n}=98$ ). In this instance, a parent post received two codes. The authors discussed cases where two codes were initially applied, and a single code was chosen prior to performing network analysis. Mobilization was determined to be the dominant theme in 24 of the 98 posts originally coded as both mobilization and one other code. 
Following the coding, the researchers built a weighted social network from the electronic trace data utilizing three units of analysis: day, parent post and parent post category based on previously established methods (Goggins, Galyen, \& Laffey, 2010; Goggins, Laffey, Amelung, \& Gallagher, 2010). In our construction of the network, each comment in a thread has some relationship to all the comments before it, but the strength of that relationship decays along two dimensions. First, the strength of connection between a comment and the comments immediately before it, which are displayed while a comment is being added, are strongest. Comments that occur within one hour of each other have a more significant strength of connection than comments that occur after a 1-hour window. This decay is sloped with each hour until one day is reached after of which the connection between the comments is given no weight.

After constructing the network, we perform weighted network analysis on the trace data utilizing the same three units of analysis: day, parent post and topic. We then calculate network centralization for the entire network and betweenness for each actor within that network using the TNET package (Opsahl, 2009) in the statistical software program, R. We use betweenness as a measure to discover individuals who draw in certain subgroups of individuals in the stream of discourse and play the broker role in conversational discourse and information exchanges.

\section{Research Questions}

This research seeks to understand the behavior of actors within a Facebook group utilizing social network analysis. The behavior of the different actors changes over time and is affected by both external events such as news stories and the actions of the administrators and individuals within the group. Understanding the network and how certain behaviors change over time can help to build an understanding how agenda setting mechanisms effect user behavior in virtual political groups and online spaces. 
1. What are the salient topics that the Coffee Party Administrators include on the main Facebook page to facilitate discourse?

2. How does the agenda setting activity of the administrators related to parent posts affect the network?

3. Who are the prominent actors in the network and what roles do they play based on the rate of participation and social network measures?

4. To what extent does the network evolve over time? How is this evolution related to participation rates and changes in specific parent post categories?

\section{Findings}

We present findings from an analysis of the 212 days from August 1, 2010 - February 28, 2011. This time period encompasses the 2010 Midterm Election, Lame Duck Session of Congress, and the seating of the newly elected Senators and Representatives. On

\begin{tabular}{|cc|}
\hline Number of Posts & Number of Actors \\
\hline Greater than 200 & 45 \\
\hline $50-200$ & 361 \\
\hline $5-49$ & 5,797 \\
$2-4$ & 9,275 \\
\hline 1 & 13,497 \\
\hline Total & 28,975 \\
\hline
\end{tabular}
average, there were 4.10 official Coffee Party Table 1: Categories of Actors parent posts each day. In total, there were 28,975 individuals who commented on a Coffee Party Parent Post and thus were factored into the network construction and subsequent analysis.

The participants fit into five distinct categories based on their rate of participation and these are detailed in table one. There was a small subset of highly active individuals who posted over 200 times within the comment stream to include the Coffee Party Administrators. There was also a larger set of individuals who were highly active in certain time periods or within a category of specific parent posts as detailed in later sections. Approximately $46 \%$ of the individuals who commented only did so once. 


\section{The Coffee Party Agenda}

The volume of posting and commenting in a Facebook group like the Coffee Party makes it difficult to discern a clear agenda. We coded each parent post for dominant topical theme in order to bring a broad view of the Coffee Party agenda to the surface. The cross cutting theme of mobilization - a basic activity for any political group - was dominant, along with discourse focused on setting a more formal agenda, campaign finance and "inspiring quotes". Three of these four themes are organizational in nature, and the fourth, campaign finance, represents a specific issue that the Coffee Party identifies as a significant part of their platform.

The frequency of parent post categories is detailed in table two. Most notable is the existence of 98 parent posts (11\%) focused on mobilization. These posts included requests for participants to call an elected official or attend a meeting. These mobilization messages were often coupled with other news stories that served as an impetus for the call to action on behalf of the group.

The three most prevalent parent post categories included: Defining the Platform $(n=88)$, Quotes (inspiring or relevant, historical quotations by well known people) $(n=82)$ and Campaign Finance ( $n=81$ ). The parent post category "Defining the Platform" was assigned to those parent posts that included a message that identified and further developed the views and beliefs of the Coffee Party as a whole. These parent posts mostly focused on the encouragement of open dialogue and civility. The parent post category "Quotes" was assigned to parent posts that included a quote from a famous individual such as a President, social leader or popular culture icon. This parent post category often sparked a significant amount of participation and was the most centralized parent post category in our data set because a core set of conversation participants remained close together across the numerous parent posts categorized as quotes. 
The parent posts that focused on campaign

finance were often accompanied with a call for mobilization, as it is one of the Coffee Party's fundamental ideologies to limit the influence of money in the electoral process in the United States. The parent post category "Campaign Finance" was assigned to all of the parent posts that were related to the Citizens United Supreme Court ruling. As well, we included all articles pertaining to the influence of money in elections. A separate category was established for Campaign Finance as opposed to including them in the "Defining the Platform" in an effort to better develop granularity in

\begin{tabular}{lc} 
Parent Post Category & Frequency \\
\hline Campaign Finance & 81 \\
Congress & 38 \\
Convention & 23 \\
Defining the Platform & 88 \\
Economy & 77 \\
Election 2010 & 46 \\
Employment & 25 \\
Environment & 25 \\
\hline Giffords & 25 \\
Health Care & 16 \\
\hline Immigration & 16 \\
International & 18 \\
Media & 24 \\
Mobilization & $98 / 24$ \\
Organizational Info & 19 \\
Quotes & 82 \\
Religion & 16 \\
Middle East Revolution & 42 \\
Security & 22 \\
Social & 36 \\
\hline State of Society & 46 \\
State of the Union & 8 \\
Spending & 18 \\
Tax & 44 \\
Wisconsin & 13 \\
\hline Total & $\mathbf{8 7 2}$ \\
\hline
\end{tabular}

Table 2: Parent Post Categories

salient theme and to reach coding saturation. A significant amount of activity in the middle to late January 2011 corresponded with a meeting in Washington, D.C. to protest the one-year anniversary of the Supreme Court Case, Citizens United. This activity generated a significant increase in the number of parent posts during the timeframe relating to Campaign Finance.

The other parent post categories received varying amounts of participation levels depending on the topic as illustrated in later sections. The inclusion of a specific parent post on the main group page was often temporally associated with salient news events. Therefore, many of the parent post categories such as "Convention", "Giffords" and "Middle East Revolutions" only appear in small subsets of the temporal data. Categories such as "Employment", "Spending" and "Social" are relatively steady over longer periods of time, as they were often the result of a 
news story pertaining to new employment figures or a budgetary proposal that occurred over a longer period of time.

\section{Participation by Parent Post Category}

The parent post categories elicited varied levels of responses from the group in relation to their overall prevalence in the group. The below figure illustrates the difference between the comments a parent post category received and the percentage of overall parent posts that that the category comprised. The plotting of the difference between these two figures allows for the identification of parent post categories that attract a disproportionate amount of comments in relation to their inclusion on the page. Positive differences in the below graph illustrate parent post categories that received a higher percentage of comments compared to the overall number of the parent posts. This illustrates a greater interest among the participants in the discourse.

The parent post category "tax" received $7.82 \%$ of total comments, but only comprised $5.05 \%$ of the total parent posts, a difference of almost $3 \%$. This illustrates a high level of interest among participants in the discourse leading to more comments. This occurrence is likely a result of the controversial nature of extending the Bush era tax cuts that occurred during the lame duck session of Congress. Similar disparities occurred in the parent post categories of Giffords, Wisconsin and Tax.

An inverse disparity occurred in the parent posts related to the Middle East Revolution and Campaign Finance. In total, $4.82 \%$ of the total number of parent posts were focused on the early 2011 Middle East Revolutions, yet only $2.78 \%$ of the total comments were contributed to these posts. Similarly, 9.29\% of the total parent posts were focused on Campaign Finance issues, yet they only received $6.09 \%$ of the total comments. Religion and the Economy were two other parent post categories that received less attention from the group participants. 
Party leaders and participants have different degrees of interest in different topics. The Administrators have more discussions started around issues that are common in the contemporary popular press; but these are often different than the topics that people actually want to discuss online. Those parent post categories with a positive differential illustrate the interest of the group as a whole. Parent post categories with a negative differential illustrate the interests of the Coffee Party Administrators, as these topics were included on the main page more frequently. At the macro level this chart can be utilized to examine the disparity between the interests of the group and the interests of the participants.

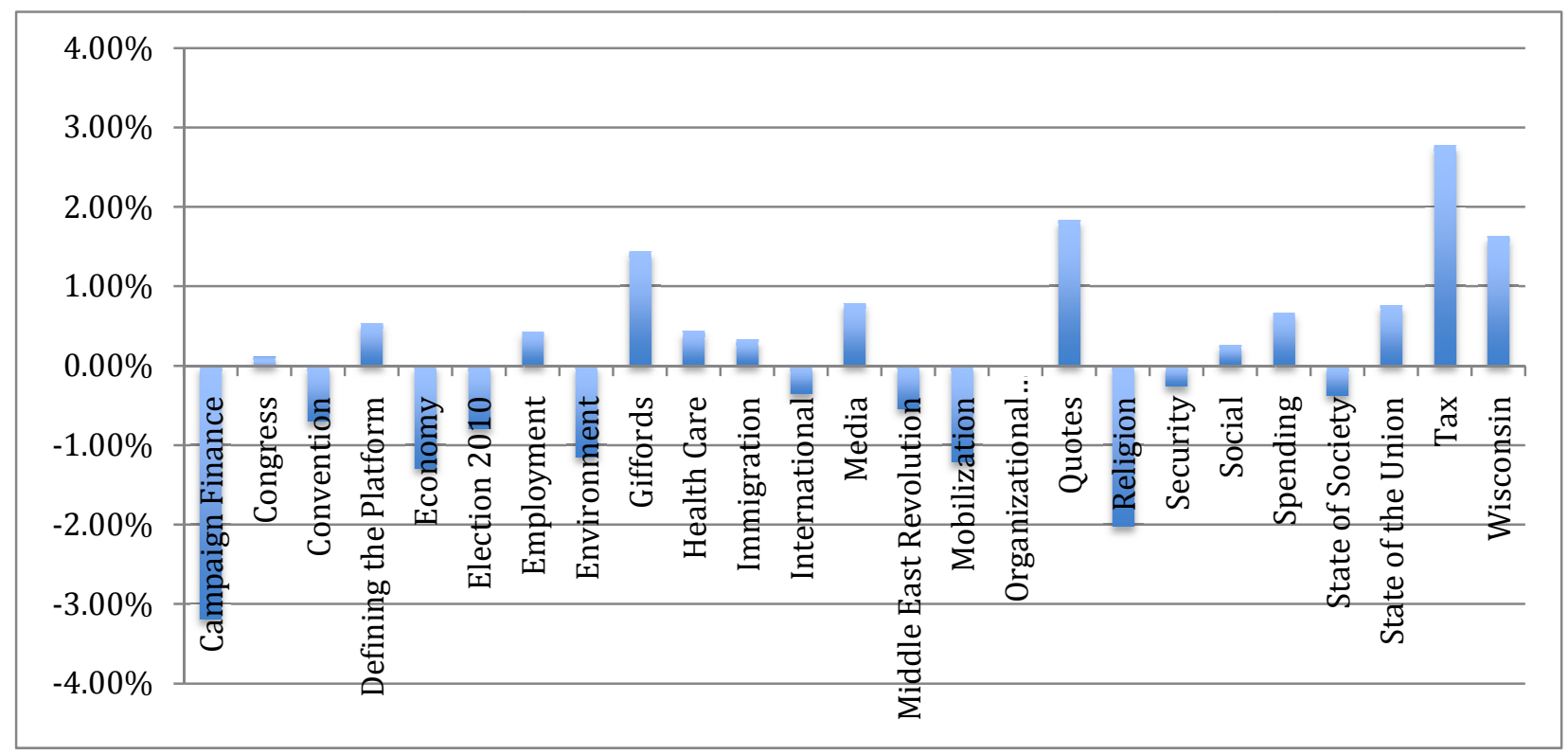

Figure 3: Differential Between Comment Percentage and Category of Parent Posts

\section{Individual Participant Behavior}

Individual participants exhibited different behavior in the various parent posts where they participate. For example, some individuals utilize the group to voice general comments to a larger set of participants, while others utilized the comment stream to engage with other, individual participants directly. We refer to the latter as "direct addressal". The direct addressal 
practices of the top contributors to the group overall illustrate that the purpose and nature of those comments varies by topic. The Coffee Party Administrators were the most prolific contributors to the discourse, but only used the automated direct addressal mechanism in $11 \%$ of the posts. Further analysis of the subset of posts by the Coffee Party administrators illustrates that at least $25 \%$ of their comments included a form of an informal direct addressal.

Much of the direct addressal behavior by the Coffee Party administrators using both the @ symbol and individual names occurred within specific, typically controversial, topic threads. The Coffee Party publicly acknowledges that comments are moderated, but these activities become more common

\begin{tabular}{|ccc|}
\hline User ID & Comments & Percent with @ \\
\hline 4077 & 1547 & $11 \%$ \\
\hline 41148 & 913 & $52 \%$ \\
\hline 41240 & 700 & $41 \%$ \\
\hline 4633 & 493 & $68 \%$ \\
\hline 4330 & 492 & $9 \%$ \\
\hline 4109 & 480 & $89 \%$ \\
\hline 10628 & 471 & $16 \%$ \\
\hline
\end{tabular}

when there are discussions that take on a negative

Table 4: Top 7 Participants in Discourse

tone. The Coffee Party administrators notify participants of their presence by posting a comment to the forum identifying themselves, and their role. If comments are judged to be a "personal attack, slur or otherwise inflammatory" statement, they are deleted. This deletion of a comment or a set of comments is often identified as occurring by the Coffee Party administrator. This moderation role places the Coffee Party in the conversation and allows for their participation to play a significant role in the construction of the network.

The utilization of the @ sign also varied significantly among the individuals who were the most prolific posters. The most prolific poster beyond the Coffee Party Administrators was user 41148. This individual self-identifies as being older and participates in an effort to try to facilitate effective and productive discussion utilizing direct addressals in 52\% of his posts. User 41148 states in his comments on numerous occasions that he is interested in having a valid 
discussion about the merit of others beliefs and does not want to engage in senseless namecalling. This user utilizes the automated direct addressals to single out other individuals who make productive, discourse contributions to the forums. Many of his comments that utilize the direct addressal are intended to encourage another participant to further clarify a point.

User 4109, a Coffee Party supporter, utilized the @ sign in $89 \%$ of his total posts, signifying an increase from previous studies that analyzed a narrower timeframe (Mascaro and Goggins, 2011). This individual utilized comments to engage in conversations with others and to voice support for a user's particular contribution to the discussion. In contrast, user 4330 only utilized the automated form of direct addressal in $9 \%$ of his posts and exhibited different behavior from the other prolific participants. Most of user 4330's comments were stated as general support of the Coffee Party's ideals of open dialogue and civility. 4330 did not utilize the direct addressal mechanism except to voice support for points from other individuals who were participating, or to single out specific participants. This behavior of singling out specific dissenters allowed him to refute specific points and highlight the dissenting behavior that was occurring within the group. The utilization of @ has an effect on the network behavior as it draws individuals into the conversation.

Key Actors in the Network by Time Period

Network analysis of the seven month time period illustrates four distinct periods of activity corresponding to different phases of the electoral cycle. These four phases are: August 1 (Day 1) - October 27 (Day 88) [Pre-election], October 28 (Day 89) - November 4 (Day 96) [Election Week], November 5 (Day 97)- January 2 (Day 155) [Lame Duck Congress] and January 3 (Day 156) - February 28 (Day 212) [New Congress]. The level of participation and the specific participants vary significantly throughout these time periods. We speculate that this 
phenomenon occurs as a result of the different political activities that take place in each phase of the election cycle. Figure one illustrates a daily computed average of network centralization based on participant activity within each specific day of activity that was analyzed.

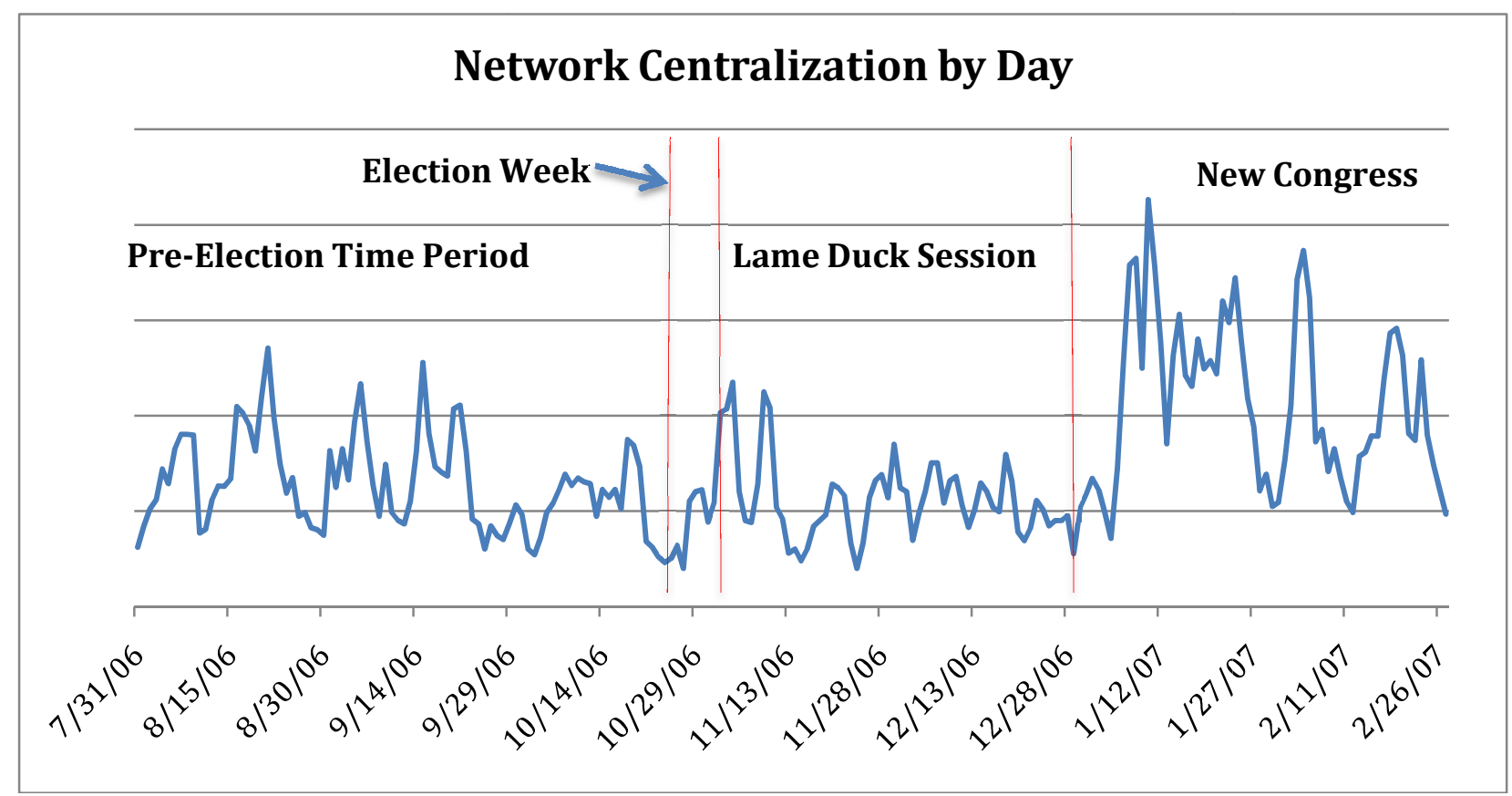

Figure 5: Network Centralization by Day

The four time periods illustrate different levels of centralization. The first two time periods that comprise the pre-election time period and the week of the election have similar centralizations. The overall centralization of the network drops by about $15 \%$ during the lame duck session of Congress. This drop in centralization indicates a decreased level of network activity among a core set of participants and more disparate groups of participants. The fourth time period is measured as having nearly twice as much centralization as time period 3 , which is likely a result of significant political events that occurred during this time period, and the ensuing, intense discussion among participants.

The week that starts the fourth time period is notable because it is when the newly elected members were seated and also the week that Arizona Representative Gabrielle Giffords was shot 
in Arizona. This is a highly active time period within the group because of the discussion surrounding her shooting and the contributing factors related to it. Many within the Coffee Party Group argued that violent political rhetoric from the "Tea Party" contributed to the shooter's motivation. Our analysis of the discourse within the parent posts, organized by topic, illustrates how the shooting generated heated discussion though there were other contributing factors.

Analysis of actors that have high levels of betweenness centrality in these different time periods illustrate the variation in topics and participant activity throughout the different time periods. Table 4 illustrates the top 10 individuals in betweenness centrality for each of the time periods. The Coffee Party Administrators appear as highest in betweenness centrality in the preelection and lame duck time period, but are number nine during election week and second during the New Congress time period. This reduction in ranking during election week is likely the result of a higher amount of informational discourse occurring within the parent posts and a possible result of specific events that are addressed in the next section. The fact that they are not number one in the time period of the New Congress is heavily influenced by user 41148 , who becomes highly active in parent post categories related to the US President's State of the Union and the Middle East Revolutions.

\begin{tabular}{ll} 
Time Period & Top 10 High Betweenness Individuals \\
Overall Time Period & $4077,41148,41240,4109,4330,4408,4560,4086,10628,5930$ \\
\hline Pre-Election & $4077,4109,4283,4945,4960,4330,5267,4633,4121,5159$ \\
\hline Election Week & $4560,5159,4957,4749,4475,5134,4408,5007,4077,4096$ \\
\hline Lame Duck & $4077,4824,4109,10628,6590,4694,4171,13713,36769,4690$ \\
\hline New Congress & 41148, 4077, 41240, 10628, 4139, 5930, 5178, 4330, 5503, 4560 \\
\hline
\end{tabular}

Table 6: Top 10 Betweenness Individuals by Time Period

Coffee Party Administrators are the only actors who are in the top 10 in betweenness centrality in all of the time periods. No other actors are ranked high in betweenness in more than 2 categories. Those actors that are ranked high in betweenness in 2 categories include: 4109 , 4330, 4560, 5159 and 10628. Of these five actors, the only one that does not appear in the top 10 
in betweenness in the overall time period is actor 5159, who is ranked 13th in overall betweenness centrality in the network. The presence of different actors in different time periods is at once fascinating and as playing an integral part in the network as measured by betweenness illustrates the network evolution over time and how different actors become more influential depending on the specific time period.

\section{Network Activity by Day}

Analyzing the network in a more granular manner enables us to examine factors that contribute to variance in network centralization within the four phases we study. The centralization of the network by day is shown in figure five, above. The day with the lowest centralization was November 25, 2010, Thanksgiving Day. This was a day with limited activity and the parent posts by the Coffee Party were also limited to apolitical sentiments like, "Happy Thanksgiving". The day with the second lowest centralization was October 28, 2010, the Thursday before the election. On this day, the activity within the Coffee Party group was mostly focused on identifying news pertaining to the election, which did not create any significant discussion. This was also the Thursday before a large rally in Washington D.C. hosted by Jon Stewart and Steven Colbert, of which the Coffee Party Administrators were attending and encouraging others to do so. It is likely that many individuals were involved in traveling to the rally as opposed to participating in the Facebook Group.

The day with the highest centralization during the period of study was January 11, 2011. On this day, there were four parent posts that did not have extremely high centralization of their own, but the combination of the four of them sparked a significant amount of discussion. Three of the four parent posts on that day were directly related to the shooting of Representative Gabrielle Giffords and the fourth post was about the upcoming anniversary of the Citizens' 
United Supreme Court decision. The combination of these four parent posts and the shooting three days earlier drew a significant amount of activity to the group as these two issues, civility and campaign finance were the foundations of the Coffee Party Platform. In total, 4 of the top 5 most centralized days in the examined time period occurred during the week of the Gabrielle Giffords shooting. This indicates a high degree of ongoing discussion among a more highly connected group than average.

The days with the highest centralization in each of the four identified time periods illustrate days in which highly salient news items of each of the specific time period were included on the Coffee Party Facebook group page. These salient news events are able to draw in significant amount of activity; and, it appears, a group of people with more intense opinions and interest in discourse than on days where less controversial topics dominate. In the pre-election time period, the day with the highest centralization was August 22, 2010. On this day, the parent posts discussed the upcoming Coffee Party convention in late September and the Coffee Party platform. Two of the four parent posts on this day were explicit calls for change in the current political system and the comments within the parent posts were focused on bringing about this change in the upcoming election. Coffee Party participants in the pre-election period are motivated by the idea of fundamental political change, and this shows up in our network analysis as high network centralization.

In the second time period, the week surrounding the election, the most centralized day was November 4, 2010. This day represented a regrouping by individuals in the Coffee Party following the Republican electoral victories and the takeover of the House of Representatives. The Coffee Party Administrators utilized the parent posts to highlight some electoral wins such as voters rejecting a plan for oil companies in California to circumvent existing environmental 
laws. The Coffee Party also included a parent post on this day to solicit ideas for what COFFEE should represent as an acronym. The parent post elicited 300 comments and many ideas including "Country Of Freedom For Everyone \& Everything" and "Citizens Organizing For Freedom, Empowerment, and Ethics."

During the third time period, the lame duck session of congress, the most highly centralized day was December 1, 2010. On this day, there were 4 parent posts that were mostly focused on health care and the economy, two of the most salient legislative items handled in the lame duck session of Congress. The overall nature of the four parent posts on that day expressed concern for the state of the economy and called for health care programs such as Medicare and Medicaid to not be cut. One of the parent posts on the economy also highlighted the release of information by the Fed of the special lending programs that it utilized during the 2008/2009 economic crises.

The most highly centralized days in the fourth time period were the days immediately following the shooting of Representative Gabrielle Giffords as the centralization of the network spiked on January 8, 2011, the day of the shooting. The highest centralized day occurred on January 11, 2011, when more information was coming out surrounding the shooting. These days illustrated a very important time within the group as the political events exemplified much of the Coffee Party's platform of civility in politics. The shooting surfaced discussion about some of the core issues that the Coffee Party Administrators were trying to advance. This highly salient news event leads to a highly centralized time period that was maintained throughout the end of the analyzed time period.

Network by Parent Post

Temporal analysis of the network by day illustrates how behavior varies over time during 
the period of study. Using each specific parent post as a unit of analysis allows for further analysis of the type of information and content of parent post that lead to increases in network centralization. Parent posts surrounding salient and controversial items in the news tended to measure as more highly centralized as they drew in conversation between individuals. The below table illustrates the centralization of each of the 872 parent posts.

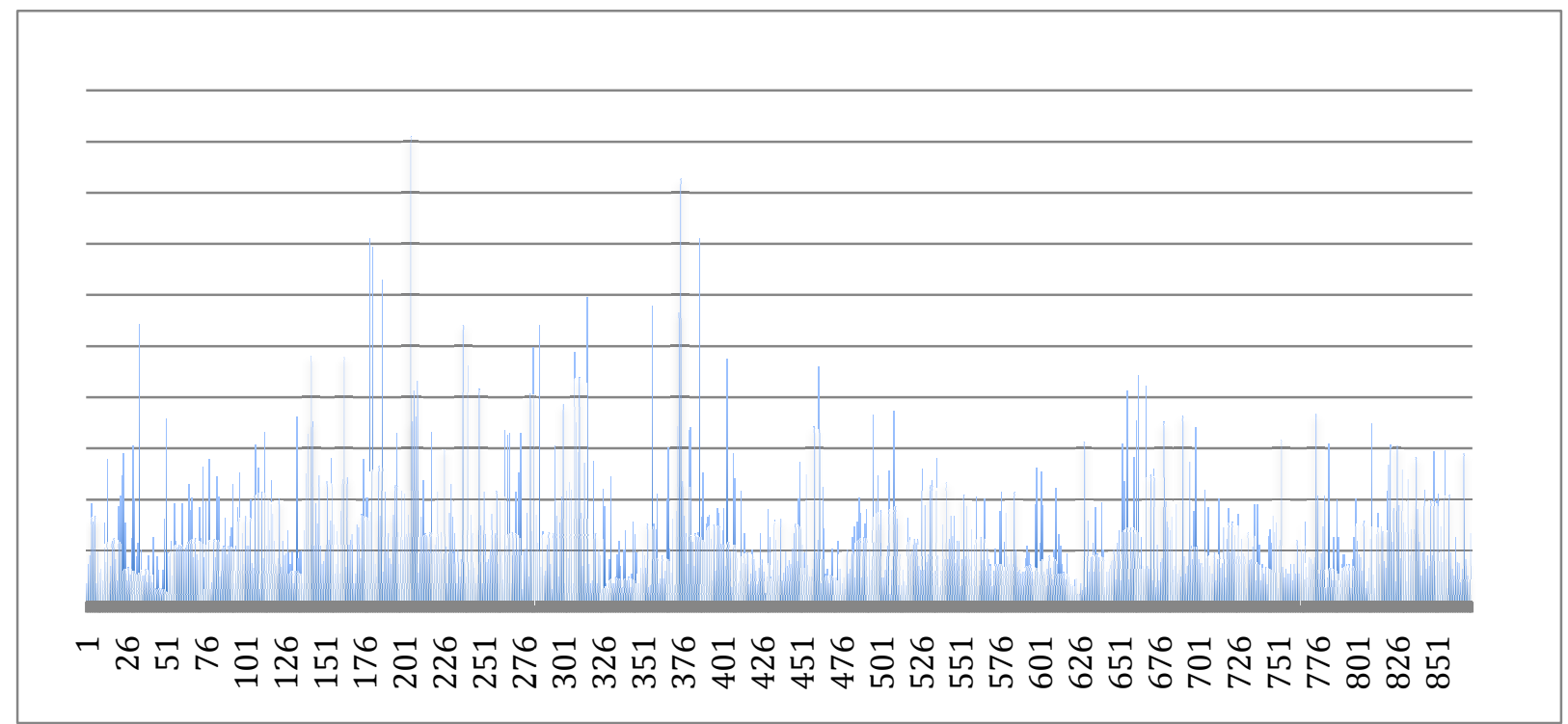

Figure 7: Network Centralization by Parent Post

The most highly centralized parent post of the whole time period occurred on September 21, 2010. This parent post discussed the pending Senate vote on the passage of the "Don't Ask, Don't Tell" and DREAM Act Amendments. This parent post received 362 comments and had 144 individuals participate in the conversation. In total, $81(23 \%)$ of the comments in that thread contained the@ @ign as a mechanism of automated direct addressal and manual coding of informal direct addressals identified another 60 comments (17\%). The conversation that occurred within the thread was mostly in support of the inclusion of these two amendments. A significant portion of the direct addressals occurred between a subset of individuals who were debating whether such measures should be enacted. Centralization at the parent post level indicates intense, material debate in our data. 
The second most centralized parent post occurred on November 3, 2010, the day after the election. This post was a summary of the current Republican gains from the previous day and projections for the outcomes of races that had yet to be decided. The parent post drew 463 comments with 258 participants with only 63 comments contained a form of direct addressal. Much of the discussion that occurred centered on what the Republican take over of the house meant for the direction of the country, with many expressing skepticism that much would change even with a new party in control. The discussion in this post appeared to be much more of a general discussion then one between specific participants as in the post about the DREAM Act.

\section{Parent Posts in Key Time Periods}

During the lame duck session of Congress the most highly centralized parent post occurred on November 21, and was an article about exiting GOP Representative Bob Inglis from South Carolina. The article received 320 comments, of which 94 contained a direct addressal. The article discusses Representative Inglis' disinterest in getting involved in name calling and buying into negative political rhetoric and how his actions along with his moderate voting record made him unpopular among his colleagues. The article asserts that Representative Inglis was voted out as a result of the Tea Party movement and further discusses his beliefs about how the current populist movement lead by the Tea Party will end. This parent post by the Coffee Party facilitated a significant discussion that agreed with the situation regarding the Tea Party and how the movement was already showing some signs of slowing down after the electoral victories two weeks earlier.

The fourth time period that included the seating of the New Congress was interesting because it had many days of highly centralized activity, but the parent posts during that time were not highly centralized compared to parent posts that occurred during the other time periods. 
The most highly centralized parent post in the fourth time period was a parent post from January 9 that received 574 comments with 109 direct addressals. This article discussed Representative Giffords shooting, but more specifically discussed the killing of the 9-year old Christina Green who was also shot. The comments within the parent post expressed their condolences for the tragic situation, but within the post there was also a conversation between participants that occurred about the motivating factor behind the shooting.

Though there were no parent posts that were highly centralized within the fourth time period, the overall network centralization was greater than any other time period as illustrated during the previous section. This is likely the result of the events of the New Congress leading to more debate about the direction of the country and also the fact that the shooting of Representative Gabrielle Giffords and the events surrounding it personified the platform of the Coffee Party of open and civil dialogue. The sustained high centralization within the fourth time period was also a result of two significant series of events the Middle East Revolutions and the state budget debate in Wisconsin. These two news events received significant amounts of attention on the page and were highly controversial and illustrated two significant events.

\section{Important Actors by Parent Post Category}

Through analysis of high betweenness individuals in the topical categories of the parent posts it is possible to understand the important roles that certain individuals play in shaping specific discourse within parent post categories derived from our thematic coding. The presence of prolific posters as high betweenness actors in a subset of categories is novel in the sense that it illustrates a specialization of comment activity that other analysis does not uncover. The Coffee Party Administrators have the highest betweenness in 12 of the 25 parent post categories and are in the top 10 actors in 7 of the 25 parent post categories. The 6 parent post categories that the 
Coffee Party Administrators were not in the top 10 in betweenness were Environment, Health Care, Giffords, State of the Union, Tax and Middle East Revolutions. The existence of the Coffee Party Administrators as actors with high betweenness in a significant number of categories suggests which parent post categories that the Coffee Party Administrators deemed to be most the most relevant to their platform; and clearly shows where they exerted the most effort.

In three of the six categories (Environment, State of the Union, Middle East Revolution), that the Coffee Party Administrators played a less significant meditational leadership (high betweenness centrality) role, the second most prolific individual, user 41148, was the most highly between individual. In another category (Giffords), the third most prolific participant, user 41240, was the individual with the highest betweenness. These two actors also had high betweenness in many of the categories in which the Coffee Party Administrators were high in betweenness.

Analysis of user's 41148 and 41240 postings shows that much of their activity was commensurate with stated platform positions of the Coffee Party such as open and civil dialogue and the attempt to understand both sides of the issue. In addition to being the most highly between individuals in these categories, user 41148 was also the most prolific poster in the Environment and State of the Union categories and the second most prolific poster in the Middle East Revolution category and user 41240 was the most highly between individual in the category of Giffords.

There are two parent post categories where the highest betweenness individuals appear to have specialized knowledge of the topic, and were not Coffee Party Administrators (Health Care, Tax). These individuals participated very little in other topics. User 5406 was the most highly 
between individual in the category of Health Care and user 13713 was the most highly between individual in the category of Tax.

Health Care: User 5406 made 110 comments throughout the 212-day time period, of which 87 (79\%) were made within those parent posts coded as Health Care. This was the most of any individual within that parent post category. These comments were made within a set of 6 parent posts from November 29 2010, - January 18, 2010, illustrating a prolonged participation period. In 4 of the 6 parent posts, user 5406 made at least 12 comments and as many as 32 in one of the parent posts. The parent post that user 5406 contributed 32 comments to was a link to an article about cutting the deficit by eliminating health care benefits that employers offer. Within this parent post, 27 of the 32 comments made by user 5406 were addressed to other individuals within the comment stream who made disparaging remarks about the health care system.

Tax: Similarly, user 13713 made 86 total comments, of which 64 (74\%) were made within parent posts coded as Tax. This placed user 13713 as the $5^{\text {th }}$ most prolific poster within the parent post category Tax. These comments were mostly evenly split between a set of 13 parent posts that occurred between December 6, 2010 - December 17, 2010 a time in which the there was a significant debate going on about whether to extend Bush Era tax cuts. User 13713 commented 22 times in a parent post on December 9, 2010 that discussed the rejection of the current tax bill without further changes. Within the context of the parent post, user 5406 engaged with other individuals who were arguing that these tax cuts were needed in their current iteration during the economy. It was during these comments in the context of the parent post that user 5406 identifies himself as an individual who is participating in the Coffee Party to protest the Tea Party and what they are doing to the economy and the current political atmosphere. 
We performed a thorough analysis of the topics, time, individual behavior and social networks associated with discourse on the Facebook site, "Join the Coffee Party Movement". Indepth qualitative analysis coupled with quantitative social network analysis allows for better identification of individuals who play a significant and important role in certain slices of the network. Network variation by time period, topic thread and thematic code each provide us with a specific view of the discourse in the Coffee Party. In the discussion section, we suggest how the interaction between these specific perspectives and the overall activity of the group are significant.

\section{Discussion}

There are three important implications that emerge from our analysis of the Coffee Party on Facebook. First, by looking at how political discourse emerges through social media from multiple perspectives we build a more complete view of how groups form, how political agendas are set and how these all vary over time. We show temporal, post specific and header code specific views to identify the key individuals and the interesting network dimensions that emerge. For example, we know that the centralization of the network on the Coffee Party site is greatest after the lame duck session, when the newly elected Congress, opposed to many of the ideas advocated on the Coffee Party page, is installed. Centralization of a political discourse network seems, then, to increase when a group is, quite literally, regrouping after defeat. These are human political behaviors we might intuit from experience. Our work demonstrates how to identify these types of phenomena is technologically mediated political discourse.

We also see how different individuals play different roles in each phase, and how the participation of members is different depending on the header code. Some people only participate in topical discussions on which they have specialized knowledge; others participate 
more broadly. We show how betweenness centrality, applied to these electronic traces of interaction, surfaces such differences. Network analysis along three dimensions: day, parent post and parent post category illuminate the varying effects of parent posts on different aspects of the network. Within the group, actors respond differently to the various parent posts that are a reflection of the external political atmosphere and events.

The second implication of this work is that for political communication in social media, political networks researchers ought to consider the extent to which the message is the medium. This inversion of Macluhan's (1994) classic argument that the "medium is the message" comes out of our observations that political discourse on the Coffee Party page is not structurally different than any Facebook group page. What distinguishes it are the topics posted, the extent of response and the ways that people interact with each other in this type of discourse. In Macluhan's view, the historical observation is that changes to the structure of communication in society effect change in society. He provides several examples. However, one of the exceptions he notes is the difficulty that historian Arnold Toynbee had pulling apart and understanding culture in the United Kingdom. The reason for this difficulty is that because of a long oral tradition, and of course the long-standing use of the English Language, patterns of power exchange and behavior were more localized in the UK than elsewhere. Facebook groups hold much of this same, local culture. In these cases, the message constructs the medium. How Facebook groups are used by political organizations define the local group; and the sorts of messages that draw people in to participate are more likely to persist than those with no response. The environment is discursive, but it is a discourse that emerges from the citizenry. Technology is not the center; it is increasingly invisible. The message of the Coffee Party administrators and members drives the structure of discourse; the structure of the medium. 
Third, the challenge for $21^{\text {st }}$ century political networks researchers is to understand, examine, and possibly guide the use of social media for connecting human needs to government policy in the richer language of human experience; and tempering long standing focus on the language of economics as a driver for policy making. For example, ideas emerge and are developed through direct addressals in the Coffee Party. While administrators use these with relatively little frequency, falling back on broadcast oriented models of communication, members address each other. Members of the Coffee Party use this space to develop ideas and solutions and receive feedback from their like-minded peers.

\section{Conclusion: Limitations, Methodological Implications and Political Network Design}

Our findings illustrate that automated analysis of large-scale datasets for the presence of conversational discourse may be missing significant amounts of information and thus network analysis of such spaces is difficult. The lack of utilization by individuals of the @ also means that individuals who are participating the comment streams may not be made aware of comments addressed to them and thus do not respond appropriately. This may limit the amount of activity that occurs as individuals may be drawn back to the discussion if they were alerted of a comment addressed to them. This highlights a socio-technical limitation that should be overcome in future

implementations of systems that house and facilitate online discourse. In this way, studies of technologically mediated political networks will benefit from engagement with emerging research programs on various types of socio-technical systems, principally found in the growing, and increasingly global, "Information School" movement. 


\section{References}

Agre, P. E. (2004). The Practical Republic: Social Skills and the Progress of Citizenship. In A. Feenberg (Ed.), Community in the Digital Age (pp. 201-224). Rowman and Littlefield.

Bebbe, S. A., \& Masterson, J. T. (2009). Communicating in Small groups: Practices and Principles (9). Boston: Pearson Education.

Cassell, J., Huffaker, D., Tversky, D., \& Ferriman, K. (2006). The language of online leadership: Gender and youth engagement on the Internet. Developmental Psychology, 42, 436-449.

Charmaz, K. (2006). Constructing Grounded Theory: A Practical Guide through Qualitative Analysis (Introducing Qualitative Methods series). London: Simon \& Schuster.

Coleman, J. S. (1988). Social Capital in the Creation of Human Capital. The American Journal of Sociology, 94, S95 - S120.

Ellison, N., Steinfeld, C., \& Lampe, C. (2007). The Benefits of Facebook "Friends:" Social Capital and College Students' Use of Online Social Network Sites. Journal of ComputerMediated Communication, 12(2007), 1143 - 1168.

Feld, S. L. (1982). Social Structural determinants of similarity among associates. American Sociological Review, 47, 797-801.

Fisher, D., Smith, M., \& Welser, H. T. (2006). You are Who You Talk to: Detecting Roles in Usenet Newgroups. Proceedings from Hawaii International Conference on System Sciences.

Glaser, B. G., \& Strauss, A. L. (1967). The discovery of grounded theory. Chicago: Aldine.

Goggins, S., Galyen, K., \& Laffey, J. (2010). Network Analysis of Trace Data for the Support of Group Work: Activity Patterns in a Completely Online Course. Proceedings from ACM Group, Sanibel Island, FL.

Goggins, S., Laffey, J., Amelung, C., \& Gallagher, M. (2010). Social Intelligence in Completely Online Groups. Proceedings from IEEE Conference on Social Computing, Minneapolis, $\mathrm{MN}$.

Gonzalez-Bailon, S., Kaltenbrunner, A., \& Banchs, R. E. (2010). The structure of political discussion networks: a model for the analysis of online deliberation. Journal of Information Technology, 2010, 1-14.

Hersey, P., \& Blanchard, K. (1992). Management of organizational behavior: Utilizing human resources (6). Englewood Cliffs, NJ: Prentice Hall.

Hill, K. A., \& Hughes, J. E. (1997). Computer-Mediated Political Communication: The 
USENET and Political Communities. Political Communication, 14(1), 3-27.

Huckfeldt, R., \& Sprague, J. (1987). Networks in Context: The Social Flow of Information. American Political Science Review, 81(4).

Kavanaugh, A., Perez-Quinones, M. A., Tedesco, J., \& Sanders, W. (2010). Toward a Virtual Town Square in the Era of Web 2.0. International Handbook of Internet Research, 2010, 279-294.

Kelly, J., Fisher, D., \& Smith, M.). Debate, division and diversity: Political discourse networks in USENET Groups. Proceedings from Online Deliberation Conference, Stanford University.

Kushin, M. J., \& Kitchener, K. (2009). Getting political on social network sites: Exploring online political discourse on Facebook. First Monday, 14(11).

Lampe, C., Ellison, N., \& Steinfeld, C. (2007). A Familiar Face(book): Profile Elements as Signals in an Online Social Network. Proceedings from Computer Human Interaction, San Jose, CA.

Lampe, C., Ellison, N., \& Steinfeld, C. (2006). A Face(book) in the Crowd: Social Searching vs. Social Browsing. Proceedings from ACM - Computer Supported Cooperative Work, Banff, Alberta.

Lazer, D., Rubineau, B., Chetkovich, C., Katz, N., \& Neblo, M. (2010). The Coevolution of Networks and Political Attitudes. Political Communication, 27(3), 248-274.

Lazer, D. (2011). Networks in Political Science: Back to the Future. PS: Political Science and Politics, 44(1), 61-68.

Marsden, P. V. (1987). Core discussion networks of Americans. American Sociological Review, $52,122-131$.

Mascaro, C., \& Goggins, S. (2011). Brewing Up Citizen Engagement: The Coffee Party on Facebook. Proceedings from Communities and Technologies, Brisbane, Australia.

Mascaro, C., Novak, A. \& Goggins, S. (2011). Networks of Discourse: An Analysis of the Conversation Surrounding a Salient News Event. under review

McLuhan, M. (1994). Understanding Media: The Extensions of Man. Cambridge: The MIT Press.

McClurg, S. (2003). Social Networks and Political Participation: The Role of Social Interaction in Explaining Political Participation. Political Research Quarterly, 56, 448-464.

Opsahl, T. (2009). Structure and Evolution of Weighted Networks. Ph.D. University of London, 
London, UK.

Rainie, L. (2011). The Internet and Campaign 2010. Retrieved from

http://www.pewinternet.org/Reports/2011/The-Internet-and-Campaign-2010.aspx

Robertson, S. P., Vatrapu, R. K., \& Medina, R. (2009). The Social Life of Social Networks:

Facebook Linkage Patterns in the 2008 U.S. Presidential Election. Proceedings from International Digital Government Research.

Robertson, S. P., Vatrapu, R. K., \& Medina, R. (2010). Off the wall political discourse: Facebook use in the 2008 U.S. Presidential election. Information Polity, 15, 11-31.

Spink, A., \& Cole, C. (2001). Information and Poverty: information-seeking channels used by African American low-income households. Library \& information Science Research, 23, 45-65.

Sweetser, K. D., \& Weaver Lariscy, R. (2008). Candidates Make Good Friends: An Analysis of Candidates' Uses of Facebook. International Journal of Strategic Communication, 2(3), 175-198.

Tajfel, H., \& Turner, J. (1986). The social identity theory of intergroup behavior. Chicago: Nelson-Hall.

Valenzuela, S., Park, N., \& Kee, K. F. (2009). Is There Social Capital in a Social Network Site?: Facebook Use and College Students' Life Satisfaction, Trust, and Participation1. Journal of Computer-Mediated Communication, 14(4), 875-901. doi:10.1111/j.1083-

6101.2009.01474.x

Williams, C., \& Gulati, G. J. (2009). Facebook Grows Up: An Empirical Assessment of its Role in the 2008 Congressional Elections. Proceedings from Midwest Political Science Association, Chicago.

Williams, C., \& Gulati, G. J. (2008). What is a Social Network Worth? Facebook and Vote Share in the 2008 Presidential Primaries. Proceedings from American Political Science Association, Boston.

Williams, C., \& Gulati, G. J. (2007). Social Networks in Political Campaigns: Facebook and the 2006 Midterm Elections. Proceedings from American Political Science Association, Chicago. 